\title{
Tuner Device
}

National Cancer Institute

\section{Source}

National Cancer Institute. Tuner Device. NCI Thesaurus. Code C50240.

An electronic receiver designed to capture signals of a selected frequency for amplification. 